\title{
Організаційні аспекти використання інтернет- маркетингу в діяльності фрітнес-клубу
}

\section{Наталія Середа}

Харківська державна академія фрізичної культури, Харків, Україна

Мета - визначити організаційні аспекти використання Інтернет-маркетингу в діяльності фрітнес-клубу. Матеріали і методи: у дослідженні використовувались наступні методи дослідження: аналіз літературних джерел та документів, анкетування, методи маркетингового аналізу, методи математичної статистики. Дослідження проводило- ся на базі 5 фітнес-клубів м. Харкова. Усього у дослідженні прийняли участь 75 осіб. До складу респондентів входили: директори, заступники директора, адміністратори, інструктори, тренери.

Результати: на підставі проведеного маркетингового аналізу сформовано загальну картину можливостей мережі lнтернет у маркетинговій політиці фітнес-клубу.

Висновки: у результаті проведеного дослідження узагальнено інформацію стосовно особливостей використання мережі Інтернет в діяльності фрітнес-клубу. Наведено результати проведеного анкетування стосовно особливостей використання Інтернет-маркетингу в організаційно-управлінській діяльності фрітнес-клубу.

Ключові слова: маркетина, Інтернет, фрітнес-клуб.

\section{Вступ}

Глобальні масштаби процесу входження Інтернету в різні аспекти життєдіяльності людини та фрізкультурноспортивної організації створили новий напрямок в організаційно-управлінській діяльності. Бурхливий розвиток електронної комерції та Інтернет-маркетингу зумовив необхідність зміни підходів до управління рекламною діяльністю фрізкультурно-спортивною організацією, особливо в Інтернет-середовищі. Одним з найбільш динамічних та ефективних інструментів рекламного менеджменту в умовах інтенсивного розвитку та розповсюдження інформації стає Інтернет (Ілляшенко С.М. 2011, Бондар А.С., Мамай В.С. 2016)

Мета дослідження - визначити організаційні аспекти використання Інтернет-маркетингу в діяльності фітнес-клубу.

\section{Матеріал і методидослідження}

У дослідженні використовувались наступні методи дослідження: аналіз літературних джерел та документів, анкетування, методи маркетингового аналізу, методи математичної статистики. Дослідження проводилося на базі 5 фрітнес-клубів м. Харкова. Усього у дослідженні прийняли участь 75 осіб. До складу респондентів входили: директори, заступники директора, адміністратори, інструктори, тренери.

\section{Результати дослідження}

Проведений аналіз літературних джерел дав змогу дійти висновку, що поняття реклами в Інтернеті не $є$ новим, але все ще $є$ недостатньо вивченим. Дослідження окремих аспектів цього явища можна знайти в працях відомих учених та авторитетних практиків І. Литовченко (2008, 2011), М. Окландера (2008), І. Квента (2009), С. Ілляшенко (2011). Більшість з названих авторів розглядають Інтернет-рекламу як складову комплексу Інтернетмаркетингу, зокрема, М. Окландер пропонує комплекс Інтернет-маркетингу розглядати з п'яти елементів: ре- клама, PR, стимулювання збуту, пошукова оптимізація та віртуальні спільноти (Окландер М. 2008).

Основні відмінності мережі Інтернет від інших каналів поширення реклами полягають у такому:

- вплив на потенційного споживача в Інтернеті відбувається за декількома каналами одночасно (банерна реклама, блоги, пошукові системи, Інтернет-ЗМІ тощо), причому канали взаємодіють між собою й дають складний сумарний ефект;

- ефрект від маркетингових дій у мережі Інтернет виявляється дуже швидко, що дає змогу отримувати перших споживачів уже на наступний день після запуску рекламної кампанії;

- користувачі мережі Інтернет миттєво реагують на нові події й охоче діляться між собою враженнями у блозі, публічних коментарях та соціальних мережах. Ця реакція може бути як негативною, так і позитивною, що посилює ефект від реклами (Квента И. 2009, Литовченко І.Л. 2011).

Щоб вирішити задачу по формуванню і пропаганди здорового способу життя необхідно, збільшити асортимент різноманітними спортивними виданнями (газети, журнали). Відповідна спортивна література повинна повністю задовольнити потребу споживача в інформації, а головне, щоб спортивні видання не містили рекламу і повідомлення які не сприяє здоровому образу життя. Друкарські засоби масової інформації повинні оприлюднювати інформацію стосовно про минулі і перебуваючи олімпіади і чемпіонати світу, публікувати статті про здоровий образ життя, фітнес - центрах, описувати спортивні події не тільки в Україні, але і за рубежем. За результатами проведеного аналізу літератури було сформовано основні можливості Інтернету в маркетинговій діяльності фрітнесклубу (табл.1.).

Дані досліджень вказують на те, що фрізкультурноспортивні організації мають достатні технічні умови для розвитку Інтернет-маркетингу. Рівень загальної комп'ютеризації вітчизняних фрітнес-клубів складає понад 91\%. 3 них 95,1\% мають доступ до глобальної мережі Інтернет. Найбільш активно фрітнес-клуби використовують 


\section{СЛОБОЖАНСЬКИЙ НАУКОВО-СПОРТИВНИЙ ВІСНИК:}

\section{Матеріали XIX Міжнародної науково-практичної конференції «Фізична культура, спорт і здоров'я: стан, проблеми та перспективи»}

Інтернет-технології для отримання та проведення банківських та фрінансових послуг $(87,7 \%)$; e-mail розсилка $(81,6 \%)$; отримання інформації $(80,5 \%)$; рекламної діяльності (66,6\%) (рис.1.). Поруч з цим, у маркетинговій діяльності сучасних фрітнес-клубів Інтернет використовується неповною мірою. За даними Державної служби статистики, менше $40 \%$ фрізкультурно-спортивних організацій мають власну сторінку чи web-сайт.

Оптимізацією інформації про власну сторінку та послуги у Інтернет-довідниках займається менше $50 \%$. Кожний четвертий ффітнес-клуб має одиничний досвід розміщення реклами в Інтернеті. Періодичне рекламування в мережі використовує лише $34 \%$. Використанням у роботі соціальних мереж займається 22\% фрітнес-клубів.

Таким чином, можна говорити про те, що вітчизняні фітнес-клуби неповною мірою використовують можливості Інтернет-маркетингу. Вважаємо, що це $є$ наслідком декількох чинників:

- побоювання фітнес-клубів щодо застосування складових Інтернет- маркетингу через недостатню кількість досліджень впливу Інтернет-технологій на маркетингову діяльність;

- недостатня кількість кваліфікованих працівників у процесі реалізації Інтернет-маркетингу;

- недосконалість системи державного регулювання Руйнування бар'єру на шляху впровадження Інтернетмаркетингу.

Для мінімалізації впливу негативних чинників на діяльність фрітнес-клубу пропонуємо наступні заходи:

- проведенні ґрунтовних досліджень щодо впливу Інтернет-маркетингу на економічну діяльність фрітнесклубів;

- розробленні рекомендацій щодо застосування Інтернет-маркетингу у фітнес-клубів в залежності від специфріки функціонування;

- посиленні ролі держави у стимулюванні розвитку електронного бізнесу та електронної комерції.

\section{Висновки /Дискусія}

Охарактеризовано роль мережі Інтернет як медіаканалу рекламного менеджменту в діяльності фітнес-клубу,

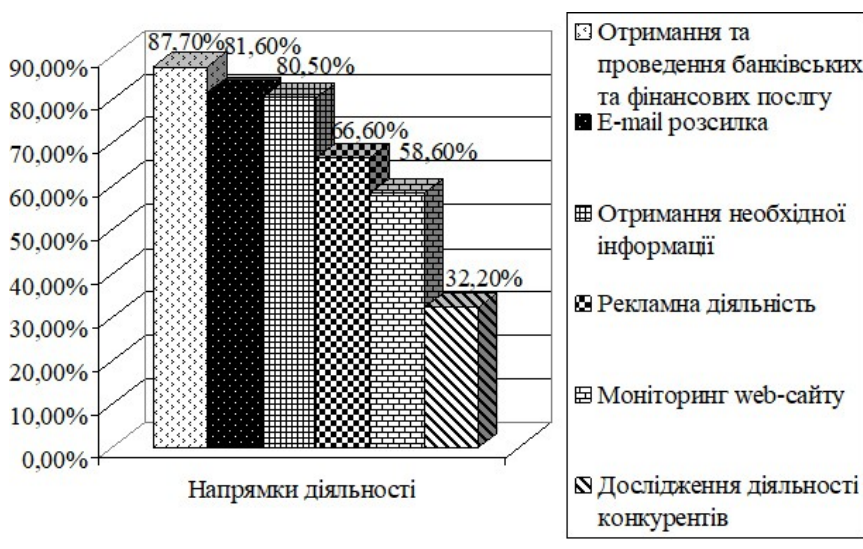

Рис. 1. Характеристика використання Інтернеттехнологій в діяльності фітнес-клубу (за результатами анкетування)

для якого характерна висока ефективність завдяки значному поширенню та можливості залучення цільової аудиторії, найактивнішою частиною якої в мережі Інтернет $є$ лідери думок, тому під час розробки рекламних.

Результати проведеного досліджень вказують на те, що фрітнес-клуби мають достатні технічні умови для розвитку Інтернет-маркетингу. Рівень загальної комп'ютеризації вітчизняних фітнес-клубів складає понад 91\%. 3 них 95, 1\% мають доступ до глобальної мережі Інтернет. Найбільш активно фрітнес-клуби використовують Інтернет-технології для отримання банківських та фрінансових послуг $(87,7 \%)$ та e-mail розсилки $(81,6 \%)$.

Узагальнюючи отримані результати дослідження визначено, що оптимізацією інформації про власну сторінку та продукцію у Інтернет-довідниках займається менше $50 \%$ фітнес-клубів. Кожний четвертий фрітнес-клуб має одиничний досвід розміщення реклами в Інтернеті. Періодичне рекламування в мережі використовує лише 34\%. Використанням у роботі соціальних мереж займається $22 \%$ фрітнес-клубів.

Перспективи подальших досліджень. Розробити організаційний план впровадження та реалізації Інтернетмаркетингу в діяльності фрізкультурно-спортивної організації.

Таблиця 1

Можливості мережі Інтернет у маркетинговій політиці фітнес-клубів

\begin{tabular}{|c|c|c|}
\hline $\begin{array}{l}\text { Складові } \\
\text { маркетингової } \\
\text { політики }\end{array}$ & Функції & Засоби Інтернету \\
\hline $\begin{array}{l}\text { Маркетингові } \\
\text { дослідження }\end{array}$ & $\begin{array}{l}\text { Дослідження ринку, дослідження конкурентів, } \\
\text { дослідження споживачів }\end{array}$ & $\begin{array}{l}\text { Аналіз веб-ресурсів конкурентів, збір інформації у } \\
\text { пошукових системах, спостереження через веб- } \\
\text { сервери, Інтернет-опитування, анкетування, фокус- } \\
\text { групи, Інтернет-розвідка }\end{array}$ \\
\hline Товарна політика & $\begin{array}{l}\text { Формування маркетингового оточення, } \\
\text { розробка нових товарів чипослуг, організація } \\
\text { сервісного обслуговування }\end{array}$ & $\begin{array}{l}\text { Участь у інформаційно-пошукових системах, } \\
\text { глобальних системах дистрибуції, глобальних } \\
\text { системах резервування }\end{array}$ \\
\hline Цінова політика & Побудова гнучкого ціноутворення & $\begin{array}{l}\text { Інтернет-аукціони, он-лайн-орендні ринки, глобальні } \\
\text { системи дистрибуції }\end{array}$ \\
\hline Збутова політика & $\begin{array}{l}\text { Збут товарів чи послуг через Інтернет, оплата } \\
\text { товарів через Інтернет }\end{array}$ & $\begin{array}{l}\text { Веб-сайт, Інтернет-магазини, Інтернет-аукціони; } \\
\text { глобальні системи дистрибуції }\end{array}$ \\
\hline $\begin{array}{l}\text { Комунікативна } \\
\text { політика }\end{array}$ & 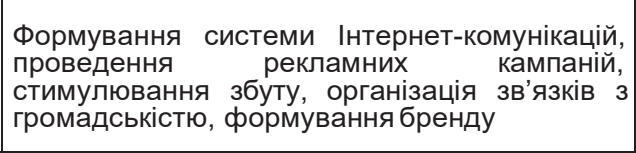 & $\begin{array}{l}\text { Банерна, контекстна реклама, оптимізація веб- } \\
\text { сайта у пошукових системах, е-таil-реклама: } \\
\text { розсилка листів, новин, дискусійних аркушів, веб- } \\
\text { сайт, Інтернет-опитування, анкетування, фокус- } \\
\text { групи }\end{array}$ \\
\hline
\end{tabular}


СЛОБОЖАНСЬКИЙ НАУКОВО-СПОРТИВНИЙ ВІСНИК:

\section{Матеріали XIX Міжнародної науково-практичної конференції «Фізична культура, спорт і здоров'я: стан, проблеми та перспективи»}

Конфрлікт інтересів. Автори заявляють, що немає конфлікту інтересів, який може сприйматися таким, що може нанести шкоду неупередженості статті. Джерела фінансування. Ця стаття не отримала фрінансової підтримки від державної, громадської або комерційної організації.

\section{Список посилань}

1. Бондар А. С., Мамай В. С. (2016), Особливості висвітлення фізичної культури і спорту в Інтернет ресурсах. Збірник наукових праць Харківської державної академії фізичної культури. Харків: ХДАФК. №3. С. 75-78.

2. Имас, Е.В., Мичуда, Ю. П., Ярмолюк, Е. В. (2015), Маркетинг в спорте: теория и практика: монографія. Киев, 228 с.

3. Ілляшенко С.М. (2011), Сучасні тенденції застосування Інтернет-технологій у маркетингу. Маркетине і менеджмент інновацій. Київ. № 4. Т. ІІ. С. 64-74.

4. Кветна И. (2009), Маркетинг в социальных сетях - ставка на доверие. Маркетинг и реклама. № 6. С. 83-89.

5. Литовченко І.Л. (2008), Методологічні аспекти Інтернет-маркетингу: монографрія. Київ: Наукова думка, 196 с.

6. Литовченко І.Л. (2011), Дослідження Інтернет-середовища України для маркетингової діяльності промислових підприємств. Маркетинг і менеджмент інновацій. № 2. С. 88-94.

7. Окландер М. (2008), Комплекс інтернет-комунікацій у маркетингу. Маркетинг в Україні. № 3 (49). С. $29-35$.

8. Sereda, N. (2015), "Analysis of the influence of marketing environment factors on the development of non-Olympic sports in sports schools (on the example of sports tourism)", Slobozhanskyi herald of science and sport : [scientific and theoretical journal]. Kharkiv KSAPC,№ 3(47), pp. 83-85.

Стаття надійшла до редакції: 11.11 .2019 р.

Опубліковано: 30.12.2019 p.

Аннотация. Наталия Середа. Организационные аспекты использования интернет-маркетинга в деятельности фитнес клуба. В статье проведен анализ использований Интернет-технологий и Интернет-маркетинга в деятельности фритнес- клуба. Предложены результаты проведенного исследования организационных аспектов использования Интенетмаркетинга в деятельности фитнес-клуба. Цель - определить организационные аспекты использования Интернет-маркетинга в деятельности фотнес-клуба. Материалы и методы исследования: анализ литературных источников и документов, анкетирования, методы маркетингового анализа, методы математической статистики. Исследование проводилось на базе 5 фитнес-клубов г. Харькова. Всего в исследовании приняли участие 75 человек. В состав респондентов входили: директора заместители директора, администраторы, иструкторы, тренера. Результаты: на основании проведенного маркетингового анализа сформировано общую картину возмож-ностей сети Интернет в деятельности фитнес-клуба. Выводы: в результате проведенного исследования обобщено инсрормацию относительно особенностей использования сети Интернет в деятельности фритнес-клуба. Раскрыто результаты проведенного анкетирования относительно особенностей использования Интернетмаркетинга в организационно- управленческой деятельности фритнес-клуба. Ключевые слова: маркетинг, Интернет, фритнес-клуб.

Abstract. Natalia Sereda. Organizational aspects of the use of Internet marketing in the activities of a fitness club. The article analyzes the use of Internet technologies and Internet marketing in the activities of a fitness club. The results of the research of organizational aspects of the use of Internet marketing in the activities of the fitness club are presented. The purpose - to determine organizational aspects of the use of Internet marketing in the activities of a fitness club. Materials and methods study: the study used the following research methods: analysis of literary sources and documents, questionnaires, methods of marketing analysis, methods of mathematical statistics. The study was conducted on the basis of 5 fitness club in Kharkiv. A total of 75 people participated in the study. The respondents included: directors, deputy directors, administrators, instructors, coaches. Results: on the basis of the conducted marketing analysis, an overall picture of the possibilities of the Internet in the marketing policy of the fitness club was formed. Conclusions: the study generalized information about the features of using the Internet in the fitness club. The results of the survey on the peculiarities of the use of Internet marketing in organizational and management activities of the fitness club are presented.

Keywords: marketing, internet, fitness club.

\section{References}

1. Bondar, A. S., Mamai, V. S. (2016), «Features of coverage of physical culture and sports in Internet resources». Zbirnyk naukovykh prats Kharkivskoi derzhavnoi akademii fizychnoi kultury [Collection of scientific works of Kharkiv State Academy of Physical Culture]. Kharkav: KhSAPC. №3. PP. 75-78. (in Ukr.).

2. Illiashenko, S.M. (2011), "Current trends in the use of Internet technologies in marketing". Marketynh i menedzhment innovatsii [Marketing and innovation management]. Kiev № 4. T. II. PP. 64-74. (in Ukr.).

3. Kvetna, I. (2009), "Social media marketing is a bet on trust". Marketing i reklama [Marketing and advertising]. № 6. PP. 83-89. (in Russ.). 4. Lytovchenko, I.L. (2008), Metodolohichni aspekty Internet-marketynhu: monohrafiia [Methodological aspects of Internet- marketynhu: monohrafiia]. Kiev: Naukova dumka, 196 p. (in Ukr.).

5. Lytovchenko, I.L. (2011), "Research of Internet environment of Ukraine for marketing activity of industrial enterprises".Marketynh i menedzhment innovatsii [Marketing and innovation management]. № 2. PP. 88-94. (in Ukr.).

6. Oklander, M. (2008), "Complex of Internet communications in marketing". Marketynh v Ukraini [Marketing in Ukraine]. № 3 (49). PP. 29-35. (in Ukr.).

7. Sereda, N. (2015), "Analysis of the influence of markeTing environment factors on the development of non-Olympic sports in sports schools (on the example of sports tourism)", Slobozhanskyi herald of science and sport : [scientific and theoretical journal]. Kharkiv KSAPC, № 3(47), pp. 83-85. (in Ukr.).

8. Ymas, E.V., Mychuda, lu.P. \& Yarmoliuk, E.V. (2015), Marketing v sporte: teoriya i praktika: monografiya [Marketing in sports: theory and practice: monograph], Olimpiiska literatura, NUFViS, Kiev. (in Russ.).

Received: 11.11.2019.

Published: 30.12.2019. 


\section{СЛОБОЖАНСЬКИЙ НАУКОВО-СПОРТИВНИЙ ВІСНИК:}

Матеріали XIX Міжнародної науково-практичної конференції «Фізична культура, спорт і здоров'я: стан, проблеми та перспективи»

\section{Відомості про авторів / Information about the Authors}

Середа Наталія Віталіївна: к.фріз.вих., доцент, Харківська державна академія фізичної культури: вул. Клочківська 99, м. Харків, 61058, Україна.

Середа Наталия Витальевна: к.физ.восп., доцент, Харьковская государственная академия фризической культуры: ул. Клочковская 99, г. Харьков, 61058, Украина.

Sereda Nataliiya: PhD (Physikal Education and Srort), Kharkiv State Academy of Physikal Cuiture: Klochkivska str. 99, Kharkiv, 61058, Ukraine.

e-mail: sereda nataliya86@ukr.net

ORCID:0000-0002-8320-3000 